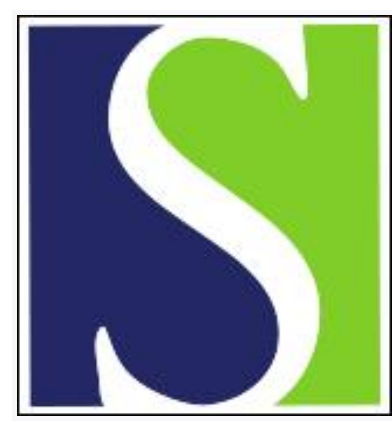

Scand J Work Environ Health 1977;3(1):36-42

https://doi.org/10.5271/sjweh.2792

Issue date: Mar 1977

Histochemical and electron microscopic observations on the myoneural junctions of rats with carbon disulfide induced polyneuropathy.

by Juntunen J, Linnoila I, Haltia M

Key terms: acetylcholinesterase; carbon disulfide; electron microscopic observation; electron microscopy; histochemical observation; histochemistry; myoneural junctions; neuromuscular junction; polyneuropathy; rat

This article in PubMed: www.ncbi.nlm.nih.gov/pubmed/847430

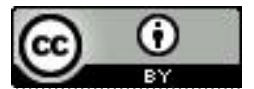




\title{
Histochemical and electron microscopic observa- tions on the myoneural junctions of rats with carbon disulfide induced polyneuropathy
}

\author{
by JUHANI JUNTUNEN, M.D., ${ }^{1}$ ILONA LINNOILA, M.D., ${ }^{2}$ and MATTI \\ HALTIA, M.D. ${ }^{3}$
}

\begin{abstract}
JUNTUNEN, J., LINNOILA, I. and HALTIA, M. Histochemical and electron microscopic observations on the myoneural junations of nats with cambon disulfide induced polyneuropathy. Scand. j. work environ. \& health 3 (1977) 36-42. Myoneural junctions in the tibiallis anterior muscle of rats with clinical signs of polyneuropathy induced with carbon disulfide were studied by light and electron microscopy. Histochemically demonstrable acetylcholinestenase (AChE; E.C. 3.1.1.7) activity was distributed similarly in the myoneural junctions of both the exposed and the control rats. In both groups intense enzyme activity was localized at the level of the postsynaptic membrane of the myoneural junction. The postsynaptic infoldings of the myoneural junctions of the exposed rats appeared normal. No enzyme activity was seen outside the zone of the myoneunal junctions. The ultrastructure of the subsarcolemmal space, as well as the postsynaptic membranes of the myoneural junctions of the exposed animals, was normal. In the terminal axons signs of various degrees of degeneration were present, e.g., disappearance of the preterminal axoplasmic neurotubules, partial disappeananoe of synaptic vesicles, appeanance of dense bodies, and even total disappearance or destruction of the terminal axons. Synaptic clefts were often widened with Schwann cell interposition. It thus seems that systemic carbom disulfide poisoning primarily alters the presynaptic structures of the myoneural junctions, while the positsynaptic side remains relatively intact, especially since the histochemical distribution of AChE in myoneural junctions was normal.
\end{abstract}

Key words: acetylcholinesterase, carbon disulfide, electron microscopy, hisitochemistry, neuromuscular junction, polyneuropathy.

It was recently shown that experimental long-term exposure to carbon disulfide $\left(\mathrm{CS}_{2}\right)$ by inhalation produces a peculiar type of toxic polyneuropathy with focal axonal swellings consisting of bundles of

1 Department of Neurology, University of Helsinki, and Department of Occupational Medicine, Institute of Occupational Health, Helsiniki, Finiland.

2 Department of Nieurology, University of Helsinki, Helsinki, Finland.

3 Second Department of Pathology, University of Helsinki, Helsinki, Finland.

Reprint requests ito: Dr. Juhani Juntunen, Department of Neurology, University of Helsinki, Haartmaninkwatu 4, FIN-00290 Helsinki 29, Finland. neurofilaments (20) and alterations in the nonspecific cholnesterase activity of intramuscular nerves (14). Neurophysiological investigations on exposed workers and rabbits have not only revealed a slowing of the maximal motor conduction velocities of peripheral nerves but also signs of disturbance at the level of the myoneural junction $(27,28)$ or muscle $(20)$. We therefore decided to study the ultrastructure of the myoneural junctions of animals exposed to $\mathrm{CS}_{2}$, particularly as, surprisingly, few morphological data are available on myoneural junctions in diffuse toxic polyneuropathies $(1,23,24,26,29)$. As there is considerable evidence suggesting that acetylcholinesterase is localized at the 
level of the postsynaptic membrane of the myoneural junction $(8,9)$ and that its activity is affected by denervation $(4,7$, 30 ), a parallel enzyme histochemical study was also carried out.

\section{MATERIAL AND METHODS}

\section{Experimental animals and exposure to carbon disulfide}

Altogether 10 adult rats of the SpragueDawley strain, 3 months old at the beginning of the exposure period, were studied in the present experiment. The animals were kept in stainless steel cages on metal grids without bedding material and were given commercial rat pellets (Orion $\mathrm{Oy}$, Helsinki, Finland) which were removed during the exposure to $\mathrm{CS}_{2}$, and water ad libitum. Seven of the rats were exposed by inhalation to an air concentration of $750 \mathrm{ppm}$ of $\mathrm{CS}_{2}$ for 4 months $(6 \mathrm{~h}$ per day, 5 days per week for the first 10 weeks, and 3 days per week thereafter). The remaining three animals, nonexposed, served as controls. For the histochemical studies material was taken from all animals, and six animals were used for electron microscopy.

\section{Histochemical methods}

The anterior tibial muscles of the rats were unilaterally removed under ether anesthesia before perfusion (or bilaterally immediately after decapitation) and fixed at $4^{\circ} \mathrm{C}$ with $3.5 \%$ formol-calcium (6) for $6-18 \mathrm{~h}$. Frozen sections were cut at $30 \mu \mathrm{m}$ and washed in distilled water for $1-3 \mathrm{~h}$.

Acetylcholinesterase (AChE; E.C.3.1.1.7) was demonstrated with the use of acetylthiocholine iodide (Fluka AG, Buchs, Switzerland) as the substrate and tetraisopropylpyrophosphoramide (iso-OMPA; L. Light \& Co, Ltd., Colnbrook, England) as the inhibitor for nonspecific cholinesterase activity.

Incubation was performed with freefloating sections at $37^{\circ} \mathrm{C}$ and at $\mathrm{pH} 6.0$ for
$2 \mathrm{~h}$ after preincubation for $20 \mathrm{~min}$ in a subtrate-free solution containing the inhibitor at a concentration of $10^{-5} \mathrm{M}$.

The intensity of $\mathrm{AChE}$ activity was estimated from a visual comparison of the activity of the exposed muscles and that of the control ones incubated in the same medium (7).

The histochemical method used in the present study was based principally on the Gomori version (10) of the Koelle technique (17).

\section{Electron microscopic methods}

Localization and dissection of the myoneural junctions in the tibialis anterior muscle for electron microscopy were performed principally according to the method described by Engel (5).

The animals were killed under ether anesthesia by perfusion, via the left ventricle, of a solution of $1 \%$ paraformaldehyde and $1.25 \%$ glutaraldehyde in $0.1 \mathrm{M}$ cacodylate buffer, $\mathrm{pH} 7.2$, followed by perfusion with $5 \%$ glutaraldehyde in the same buffer (16). After dissection of the muscle pieces the fixation was continued by immersion in the $5 \%$ glutaraldehyde solution at $4^{\circ} \mathrm{C}$ for $2 \mathrm{~h}$. Postfixation was carried out with $1 \%$ osmium tetroxide with a pH of 7.4 for $1 \mathrm{~h}$, and it was followed by dehydration with ethyl alcohol. Thereafter the pieces were embedded in an Epon-Araldite mixture (21), sectioned and poststained with uranyl acetate (31) and lead citrate (25). A Philips EM300 electron microscope was used when the sections were examined and photographed.

\section{RESULTS}

\section{Intoxication symptoms}

After 4 months of exposure to $\mathrm{CS}_{2}$ there was marked weakness in the posterior extremities of all the animals. They had considerable difficulty in moving about and were unable to support the caudal parts of their bodies adequately. 


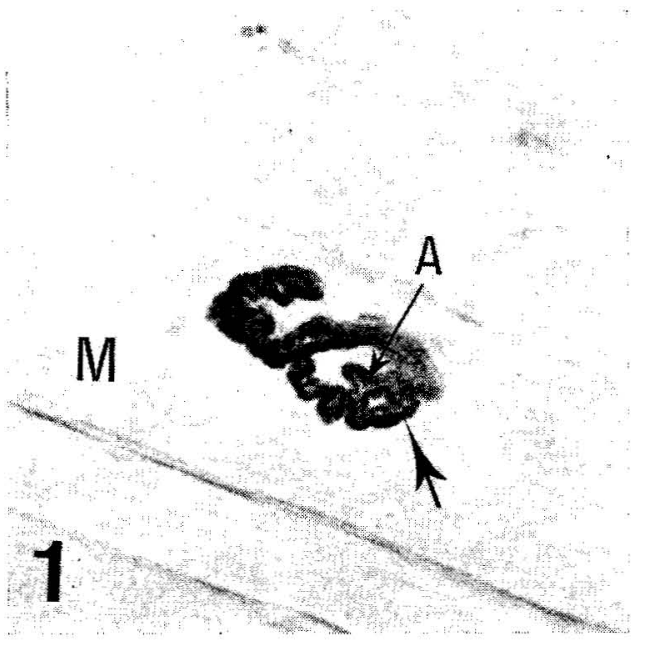

Fig. 1. Acetylcholinesterase activity in the myoneural junction on the tibialis anterior muscle of an exposed nat. Intense enzyme activity was localized along the postsynaptic membrane where the infoldings are present (arrow). The axon terminals (A) were ramified and the whole myoneural area was segmented. $(\mathrm{M}=$ muscle fiber, $\times 750)$.

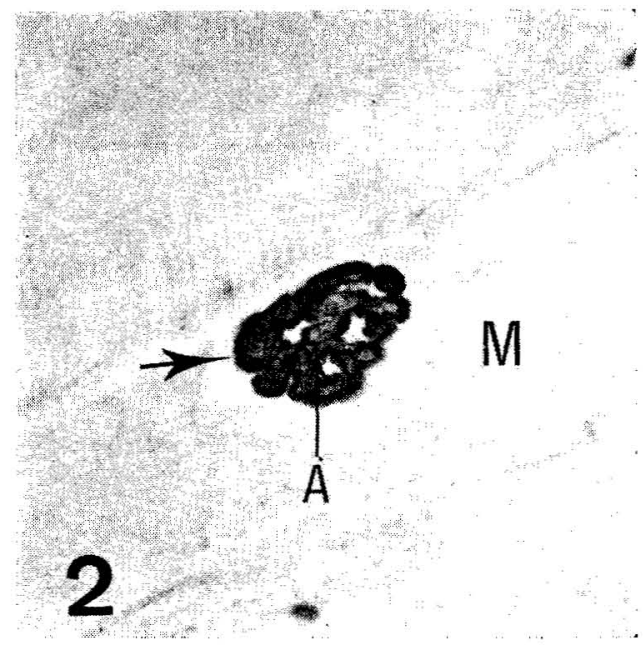

Fig. 2. Myoneural junction from the tibialis anterior muscle of a control rat. The distribution of acetylcholinesterase activity was similar to that of the exposed rats. (Arrow $=$ postsynaptic membrane with infoldings, $\times 750$ )

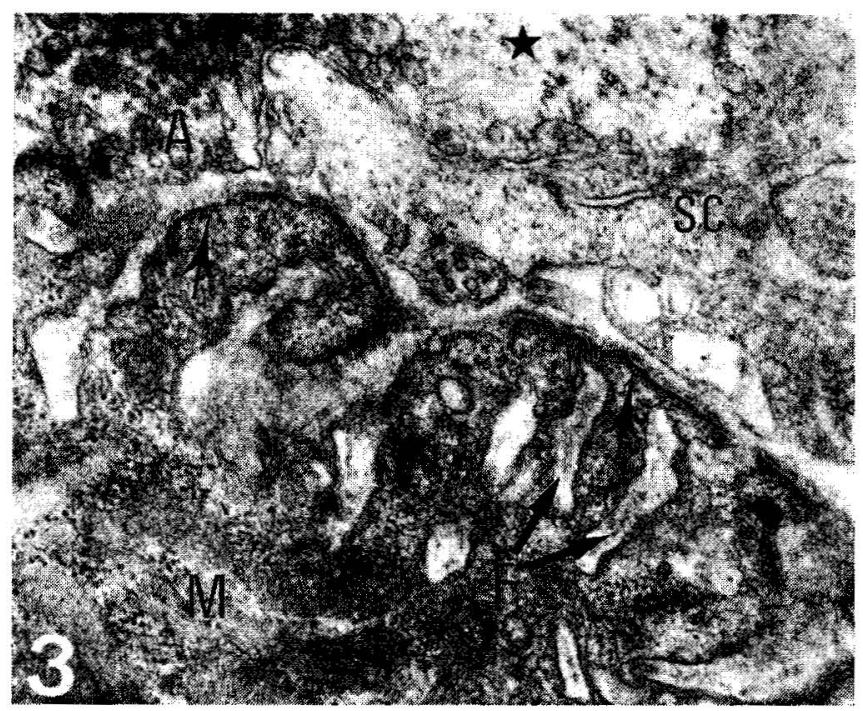

Fig. 3. Myoneural junction of the tibialis anterior muscle of a nat exposed to $\mathrm{CS}_{2}$ for 4 months. Subsarcolemmal space of the muscle (M) was normal. The postsynaptic infoldings (F) were, in general, normal although occasional irregular widenings were seen. Electron density of the postsynaptic membrane (arrows) was normal. The axon terminal (A) was partially ( $\star$ ) separated from the postsynaptic membrane by Schwann cell (SC) processes. $(\times 33500)$ 


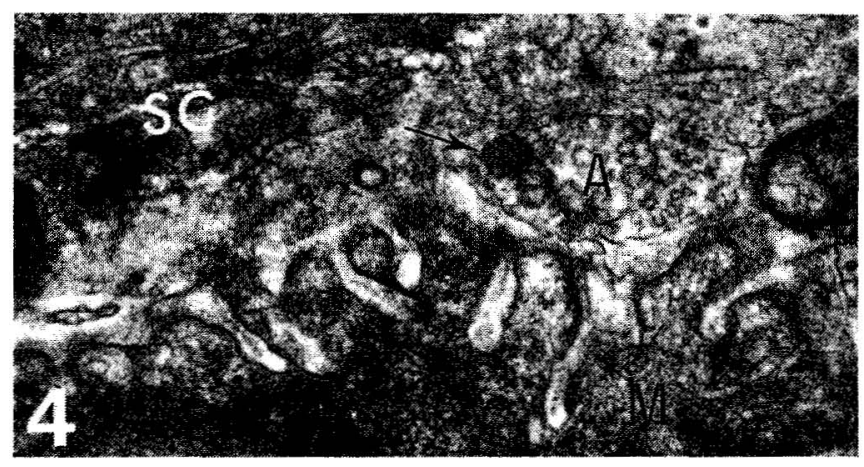

Fig. 4. A Schwann cell (SC) covered axon terminal (A) from the tibialis anterior muscle of an exposed rat. In the figure the terminal has been divided into compartments by a smooth surfaced membrane. Degenerative signs in this myoneural junction include dense bodies (arrow) in the axoplasm and advanced Schwann cell interposition. The postsynaptic infoldings and subsarcolemmal space were normal. $(\mathrm{M}=$ muscle, $\times 22000)$

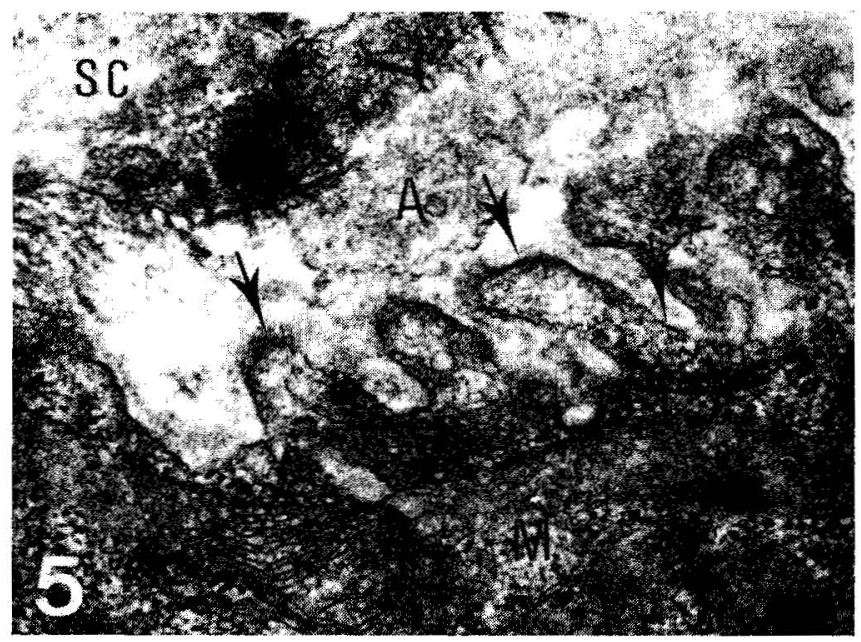

Fig. 5. Relatively far advanced degeneration in the myoneural junction of the tibialis anterior muscle of an exposed animal. Only remnants of the axon terminal (A) were left. The postsynaptic infoldings were visible (arrows), although degenerative changes could be seen in and subsarcolemmal space were normal. $(\mathbf{M}=$ muscle, $\times 22000)$ 


\section{Acetylcholinesterase activity}

In the control animals the zone of myoneural junctions with intense AChE activity formed an upward convex arch, the individual muscle fibers containing a single myoneural junction. The enzyme activity was localized in the postsynaptic part of the myoneural junction and thus revealed the postsynaptic infoldings clearly (figs. 1-2). The area of AChE activity was ramified and segmented. In most of the myoneural junctions of the exposed animals the distribution of the histochemically demonstrable $\mathrm{AChE}$ activity was normal. Degenerative changes, i.e., lowered intensity of AChE and irregular postsynaptic infoldings, were observed in only a few of the myoneural junctions. No AChE activity was seen outside the zone of the myoneural junctions.

\section{Electron microscopy}

Altogether, 13 myoneural junctions from the tibialis anterior muscle of three animals exposed to $\mathrm{CS}_{2}$ were studied with the electron microscope. Three myoneural junctions from the control group were similarly analyzed.

The subsarcolemmal space of the myoneural area of the $\mathrm{CS}_{2}$ exposed rats was normal. Most of the myoneural junctions of the exposed rats had a normal postsynaptic structure. The postsynaptic membrane of the myoneural junction was typically electron dense and deeply folded and it extended as fingerlike invaginations into the subsarcolemmal space. The bottoms of these infoldings were broader and less electron dense than their necks. Amorphous material occupied the space between the axonal and muscular membranes. Degenerative changes, i.e., irregularly shaped and lowered postsynaptic infoldings, were observed in only two of the myoneural junctions studied (fig. 5). In most of the myoneural junctions analyzed, the primary synaptic cleft was often irregularly widened and it contained only remnants of the amorphous surface material. In the myoneural junctions with a widened synaptic cleft there was usually interposition of Schwann cells, the side of the axon terminal facing the muscle thus being separated from the postsynaptic membrane (fig. 3).

Most axon terminals of the myoneural junctions of the exposed animals had signs of various degrees of degeneration. Those parts of the axons separated from the postsynaptic membrane by Schwann cell cytoplasm were often devoid of synaptic vesicles and mitochondria (fig. 3). Occasional dense bodies and irregular, membranelimited spaces were present (figs. 3 and 4). The preterminal axoplasm was also frequently devoid of neurotubules, while the number of neurofilaments had increased. Almost total destruction of the axon was observed in a few myoneural junctions, particularly in those with altered postsynaptic membranes (fig. 5). In the cytoplasm of the teloglial cells covering the most severely affected axon terminals, signs of reactive alterations were seen, including dilatation of the cisternae of the endoplasmic reticulum and appearance of inclusions in the cytoplasm.

\section{DISCUSSION}

The present findings show that in chronic polyneuropathy induced by $\mathrm{CS}_{2}$ inhalation various stages of degeneration of the myoneural junction occur that are not found in controls. The degenerative changes essentially consist of ultrastructural alterations of the presynaptic side of the myoneural junctions, while the postsynaptic side is only slightly affected.

Because of the supposed postsynaptic localization of $\mathrm{AChE}$ already mentioned, it seems conceivable, on the basis of the present ultrastructural findings, that no major changes occur in the distribution of this enzyme in the myoneural junction. In the present study no signs of local concentration of $\mathrm{AChE}$ activity outside the zone of the myoneural junctions appeared which can be considered as a lack of formation of new neuromuscular contacts during regeneration of the nerve (15). Weakening of the enzyme activity was seen only occasionally in some myoneural junctions, a finding consistent with denervation (7) as evidenced by ultrastructural observation of myoneural junctions with advanced degeneration or total destruction 
of the terminal axons. In these myoneural junctions alterations in the postsynaptic membrane also occurred which may be attributed to denervation-like changes (18).

In most of the nerve terminals of the exposed animals signs of advanced degeneration were observed with no signs of regeneration. The major ultrastructural alterations included an increase in the number of preterminal neurofilaments, a decrease in the number of preterminal neurotubules and terminal synpatic vesicles, the appearance of dense bodies and degenerating mitochondria into the axon terminals, and the interposition of the teloglial cells. Similar ultrastructural changes have been described in the myoneural junctions in association with acrylamide-induced neuropathy $(24,29)$. On the other hand, no lamellated inclusions of the axoplasm of the nerve terminal, typical of tri-ortho-cresyl phosphate intoxication (23), were observed in the present study.

Of considerable interest is the role of disturbed trophic or inductive functions of the nerve $(11,13,19)$ in the degeneration of the terminal or postsynaptic structures of the myoneural junction in polyneuropathy. There is evidence suggesting that structural changes of the axon, especially disruption of the axoplasmic neurotubules, cause inhibition of the axonal transport $(12,22)$, and consequently the delivery of a trophic substance or substances may be inhibited $(13,22)$. It is also believed that the so-called dying-back neuropathies result from failure of neuronal perikarya to supply the material required by their axons $(2,3) . \mathrm{CS}_{2}$ induced polyneuropathy is characterized by marked structural alterations of the axon that include the disappearance of the axoplasmic neurotubules $(14,20)$. Therefore, it seems probable that axoplasmic transport is inhibited to some extent. On the other hand the observation of relatively few postsynaptic structural alterations in the myoneural junctions of the exposed animals indicates that disturbances of trophic functions of the nerve do not cause any marked changes during exposure conditions similar to those applied in the present study. Considerable interspecies differences apparently exist in this respect; e.g., rabbits develop severe denervation atrophy of the muscle under identical experimental conditions (20).

\section{ACKNOWLEDGMENT}

This investigation was supported by a grant from the Finnish Cultural Foundation.

\section{REFERENCES}

1. BISCHOFF, A. Ultrastructural pathology of the periphenal nervous system. $Z$. neurol. 205 (1973) $257-274$.

2. CAVANAGH, J. B. Organo-phosphorous neuratoxicity: A model of "dying-back" process companable to certain human neunological disorders. Guys hosp. rep. 112 (1963) 303-319.

3. CAVANAGH, J. B. Toxic substances and the nenvous system. Br. med. bull. 25 (1969) $268-273$.

4. DRACHMAN, D. B. Neuratrophic regulation of muscle cholinesterase: Effects of batulinum toxin and denervation. $J$. physiol. (Landon) 226 (1972) 619-627.

5. ENGEL, A. G. Locating motor end plates for electnon microscopy. Mayo clin. proc. 45 (1970) $450-454$.

6. ERANKO, $O$. On the histachemistry of the adnenal medulla of the rat with special refenence to acid phosphatases. Acta anat. (Basel) 16 (1952): suppl. 17, $1-60$.

7. ERÄNKÓ, O. and TERÄVÄINEN, H. Cholinesterases and eserine resistant carboxylic esterases in degenerating and regenerating motor end plates of the rat. $J$. neurochem. 14 ,(1967) 947-954.

8. ERÄNKÖ, O. and TERÄVÄINEN, H. Distribution of estenases in the myoneural junction of the striated muscle of the nat. $J$. histochem. cytochem. 15 (1967) 399-403.

9. FRIEDENBERG, R. M. and SELIGMAN, A. M. Acetylcholinesterase at the myoneural junction: Cytochemical ulitrastructure and some biochemical considerations. $J$. histochem. cytochem. 20 (1972) 771-792.

10. GOMORI, G. Microscopic histochemistry: Principles and practice. The University of Chicago Press, Chicago 1952.

11. GUTH, L. "Trophic" influence of nerve on muscle. Physiol. rev. 48 (1968) 645-687.

12. HÖKFELT, T. and DAHLSTROMM, A. Effects of two mitosis inhibitors (colchicine and vinblastine) on the distribution and axonal transport of noradrenaline storage particles, studied by fluonescence and electron micnoscopy. Z. Zellforsch. Mikrosk. Anat. 119 (1971) 460-482.

13. JUNTNEN, J. Induction of the pastsynaptic membrane. Med. biol. 52 (1974) $164-169$.

14. JUNTUNEN, J., HALTIA, M. and LINNOILA, I. Histochemically demonstrable nonspecific cholinesterase as an indicator of peripheral nerve lesion in carbon disul- 
phide-induced polyneuropathy. Acta neuropathol. (Berlin) 29 (1974) 361-366.

15. JUNTUNEN, J. and TERÄVÄINEN, H. Morphogenesis of myoneural junctions induced postnatally in the tibialis anterior muscle of the rat. Acta physiol. scand. 79 (1970) 462-468.

16. KARNOVSKY, M. J. A formaldehyde-glutanaldehyde fixative of high osmolarity for use in electron microscopy. $J$. cell biol. 27 (1965) $137 \mathrm{~A}$.

17. KOELLE, G. B. The elimination of enzymatic diffusion artifacts in the histochemical localization of cholinesterases and a survey of their cellular distributions. $J$. pharmacol. exp. ther. 103 (1951) 153-171.

18. LENTZ, T. L. Development of the neuromuscular junction: IIT. Degenerartion of the motor end plates after denervation and maintenance in vitro by nerve explants. $J$. cell biol. 55 (1972) 93-103.

19. LENTZ, T. L. Neurotrophic regulation at the neuromuscular junction. Ann. $n, y$. acad. sci. 228 (1974) 323-337.

20. LINNOILA, I., HALTIA, M., SEPPÄLÄINEN, A. M. and PALO, J. Experimental carbon disulphide poisoning: Morphological and neurophysiological studies. In: S. KÖRNYEY, S. TARISKA and G. GOSZTONYI (eds.), Proceedings of the VIIth international congress of neuropathology. Académiai Kiadó, Budapest 1975, pp. 383386.

21. MOLLENHAUER, H. H. Plastic embedding mixtures for use in electron microscopy. Stain technol. 39 (1964) $111-114$.

22. OCHS, S. Fast axoplasmic transport of materials in mammalian nerve and its integnative role. Ann. n. y. acad. sci. 193 (1972) $43-58$.

23. PRINEAS, J. The pathogenesis of dyingback polyneuropathies: Part I. An ultrastructural study of experimental tri-ortho- cresyl phosphate intoxication in the cat. $J$. neuropathol. exp. neurol. 28 (1969) 571597.

24. PRINEAS, J. The pathogenesis of dyingback polyneuropathies: Part II. An ultrastructural study of experimental acrylamide intoxication in the cat. J. neuropathol. exp. neurol. 28 (1969) 598-621.

25. REYNOLDS, E. S. The use of lead citrate at high $\mathrm{pH}$ as an electron-opaque sitain in electron microscopy. $J$. cell biol. 17 (1963) 208-212.

26. SAIDA, K., MENDELL, J. R. and WEISS, $H$. Peripheral nerve changes induced by methyl $n$-butyl ketone and potentiation by methyl ethyl ketone. J. neuropathol exp. neurol. 35 (1976) 207-225.

27. SEPPÄLÄINEN, A. M. and LINNOILA, I. Electrophysiological studies on rabbits in long-term exposure to carbon disulphide. Scand. j. work environ. \& health 1 (1975) $178-183$.

28. SEPPÄLÄINEN, A. M., TOLONEN, M., KARLI, P., HANNINEN, H. and HERNBERG, S. Neurophysiological findings in chronic carbon disulphide poisoning: A descriptive study. Work-environ.-health 9 (1972) $71-75$.

29. SCHAUMBURG, H. H., WISNIEWSKI, H. M. and SPENCER, P. S. Ultrasitructural studies of the dying-back process: 1. Peripheral nerve iterminal and axon degeneration in systemic acrylamide intoxication. $J$. neuropathol. exp. neurol. 33 (1974) 260.

30. TERÄVÄINEN, H. and JUNTUNEN, J. Effeat of temporary denervation on the development of the acetylcholinesterasepositive structures of the nat myoneural junctions. Histochemie 15 (1968) 261-269.

31. WATSON, M. L. Staining of tissue sections for electron microscopy with heavy metals. $J$. cell biol. 4 (1958) 475-478. 